\title{
Letters
}

Website: www.bmj.com

Email: letters@bmj.com

\section{Number of land mine victims in Kosovo is high}

EDITOR-On 9 June 1999, the governments of the Federal Republic of Yugoslavia and of the Republic of Serbia signed a military technical agreement with the NATO-led international security force (KFOR) concerning the situation in Kosovo. During the following four weeks more than 650000 Kosovar refugees returned home. The number of people with fatal and non-fatal injuries caused by antipersonnel mines needs to be determined to plan mine awareness and demining campaigns accordingly.

On 7-14 July 1999, the World Health Organisation conducted an assessment to determine the number of people with mine injuries in Kosovo since 13 June; the circumstances in which the injuries occur; and the additional burden that their consequences impose on Kosovo's health system. Data were collected in Kosovo's six hospitals and from the database maintained by NATO forces in Kosovo. The additional number of fatalities and light injuries was estimated on the basis of interviews with the patients.

During the four weeks after 13 June, an estimated 150 people were maimed or killed by explosions of mines or unexploded ordnance in Kosovo. This corresponds to a monthly incidence rate of 10 per 100000 population (an annualised rate of 120 per $100000)$. Seventy one per cent of the survivors are younger than 24 years. Most (95\%) are boys or men. Nineteen per cent of the 75 patients interviewed were injured during demining efforts conducted by the Kosovo Liberation Army. In some areas 35\% and $42 \%$ of hospital beds in the surgical and orthopaedic wards were occupied by survivors of explosions of mines or unexploded ordnance.

After months of suffering, for those affected, returning home often has not meant returning to safety. The incidence of injuries and deaths caused by mines or unexploded ordnance exceeds that found in many other countries affected by antipersonnel mines, such as Mozambique, Afghanistan, or Cambodia. ${ }^{1.4}$ It is expected to remain high as the population has not yet started to return to the fields or pastures and the collection of firewood for the winter is expected to start in September.

Mines and unexploded ordnance are a public health problem, not only because they kill and maim, but also because they drain resources from an already depleted health system. To achieve an appropriate response, a surveillance system must be developed to monitor the situation. ${ }^{5}$ The study confirms that current efforts at raising mine awareness and demining should be encouraged and increased. Awareness raising efforts should target especially young men and children and, as in any other country, the international community should first train and equip the local deminers.

E G Krug medical officer

Violence and Injury Prevention, Department for Disability, Injury Prevention and Rehabilitation,

Social Change and Mental Health, World Health

Organisation, CH-1211 Geneva, Switzerland

kruge@who.ch

A Gjini A medical officer

World Health Organisation, Pristina, Kosovo

1 International Campaign to Ban Land Mines. Landmin monitor report. New York: Human Rights Watch, 1999:61.

2 Meddings DR, O'Connor SM. Circumstances around weapon injury in Cambodia after departure of peacekeeping force: prospective cohort study. BMJ 1999; peacekeeping

3 Michael M, Meddings DR, Ramez S, Gutiérrez-Fisac JL. Incidence of weapon injuries not related to interfactional combat in Afghanistan in 1996: prospective cohort study. BMJ 1999;319:415-7.

4 Jeffrey SJ. Antipersonnel mines: who are the victims? J Accid Emerg Med 1996;13:343-346.

5 Krug EG, Ikeda RM, Qualls ML, Anderson MA, Rosenber ML, Jackson RJ. Preventing land mine-related injury and disability: a public health strategy. JAMA 1998; 280(5):465-6.

\section{Treatment of hepatitis $\mathrm{C}$ infection}

\section{Review underplayed important public} health issues

EDIToR-We were disappointed that McCarthy and Wilkinson's review of recen advances in hepatology underplayed important public health issues and treatment options surrounding hepatitis $\mathrm{C}$ virus. ${ }^{1}$ In Western Europe about 5 million people are chronic carriers of hepatitis $\mathrm{C}$ virus, and in industrialised countries the virus accounts for $40 \%$ of cases of end stage cirrhosis and $30 \%$ of liver transplants. ${ }^{2}$ Hepatitis C is thus an important health problem.

Recent data confirm that combination antiviral treatment with ribavirin and interferon is better than interferon alone, with a $38-43 \%$ sustained response rate (polymerase chain reaction negative) with 12 months of combination treatment compared with $13-19 \%$ with interferon alone. ${ }^{3}{ }^{4}$ Although ribavirin has been supplied for use only in trials in the United Kingdom, it is imminently to be licensed for patients who relapse after interferon alone and is already licensed for this indication in the United States and other European countries.

Moreover, a recent international consensus conference on hepatitis $\mathrm{C}$ recommended that interferon and ribavirin be first line treatment for previously untreated (naive) patients without contraindication to ribavirin. Duration of treatment should be tailored to viral load and viral genotype. It was suggested that patients with viral genotype 1 should have a six month course of combination treatment before viral response to treatment is assessed compared with three months for those infected with other viral genotypes. These recommendations (drawn from a panel of experts) have important public health and economic implications.

Lastly, we are not aware of any large trials using ribavirin alone in patients with recurrent hepatitis $\mathrm{C}$ infection after transplantation as it has little in vitro activity against the virus. Preliminary data on 122 patients with chronic recurrent infection after transplantation from Italy suggest that sustained response rates of up to $50 \%$ (similar to that in chronic nonimmunocompromised hepatitis $\mathrm{C}$ infection) can be obtained safely in selected groups without precipitating graft rejection. Patients with coexistent HIV infection

\section{Advice to authors}

We prefer to receive all responses electronically, sent either directly to our website or to the editorial office as email or on a disk. Processing your letter will be delayed unless it arrives in an electronic form.

We are now posting all direct submissions to our website within 24 hours of receipt and our intention is to post all other electronic submissions there as well. All responses will be eligible for publication in the paper journal.

Responses should be under 400 words and relate to articles published in the preceding month. They should include $\leqslant 5$ references, in the Vancouver style, including one to the BMJ article to which they relate. We welcome illustrations.

Please supply each author's current appointment and full address, and a phone or fax number or email address for the corresponding author. We ask authors to declare any competing interest. Please send a stamped addressed envelope if you would like to know whether your letter has been accepted or rejected.

Letters will be edited and may be shortened.

www.bmj.com

letters@bmj.com 
should be considered for antiviral treatment of hepatitis C if HIV disease activity is stable. We must be aware of improvements in treatment options for hepatitis $\mathrm{C}$ and the public health issues surrounding these advances, particularly in an environment where health resources are finite.

Kosh Agarwal research registrar

David D E Jones MRC clinician scientis

Centre for Liver Research, The Medical School,

University of Newcastle, Newcastle NE1 7RU

Competing interests: None declared.

1 McCarthy M, Wilkinson MI. Recent advances in hepatology. BMJ 1999;318:1256-9. (8 Mav.)

2 EASL International Consensus Conference on Hepatitis C.J Hepatol 1999;30:956-61.

3 Poynard T, Marcellin P, Lee SS, Niederau C, Minuk GS, Int $\mathrm{G}$, et al. Randomised trial of interferon affob ribavin et al Ras interen ribavirin versus interferon alfa2b plus placebo for 48

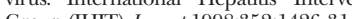
426-31.

SC, SchiffER, Shiffman ML, Lee WM, Rustgi VK, et al. Interferon alfa-2b alone or in combination with ribavirin as initial treatment for chronic hepatitis C. N Engl J Med 1998;339:1485-92

Bellati G, Alberti AB, Belli LS, Vai C, Airoldi A, Rodinara GF, et al. Therapy of chronic hepatitis $\mathrm{C}$ after liver transplantation: multicenter Italian experience. $J$ Hepato 1999;30(suppl 1A).

\section{Authors' reply}

EDIToR-Although we agree with Agarwal and Jones's comments regarding the importance of public health issues and treatment options for hepatitis $\mathrm{C}$ infection, we would like to point out that our article was aimed at providing an overall review of recent changes in hepatology for nonspecialised readers. This meant addressing several topics, and although hepatitis $\mathrm{C}$ infection is one of the more important issues, we were obliged to limit the discussion to a concise and less detailed one.

Since our article was submitted, consensus statements have made clear recommendations on the treatment of naive hepatitis $\mathrm{C}$ infection with a first line combination therapy of interferon alfa and ribavirin, which was previously still being evaluated in controlled trials. ${ }^{1}$

Such guidelines now advocate the use of combination therapy with interferon alfa and ribavirin in naive patients without contraindication. Treatment for six months is advised for patients with genotype 2 or 3 , irrespective of levels of viraemia. However, for those with genotype 1, treatment should be for six months if viraemia is low $(<2$ million copies/ml) but for 12 months if viraemia exceeds this level. If ribavirin is contraindicated, interferon should be offered alone for 12 months (3 MU three times a week), with continuation of therapy after three months only in those whose hepatitis C viral RNA has disappeared. Patients who have relapsed after treatment with interferon, can be given either six months of combination therapy or a higher dose of interferon alfa for 12 months.

Treatment of recurrent hepatitis C infection after transplantation has recently been comprehensively reviewed by Berenguer et al. ${ }^{2}$ Results of preliminary open label studies of ribavirin monotherapy have been disappointing with respect to viral clearance, ${ }^{34}$ and more recent studies have concentrated on combination therapy with interferon alfa and ribavirin with promising initial results. ${ }^{5}$

M McCarthy senior specialist registrar

M Wilkinson senior lecturer

Department of Gastroenterology, Guy's Campus, GKT Medical School, London SE1 9RT

Competing interests: None declared.

1 EASL international consensus conference on hepatitis C. J Hepatol 1999;30:956-61.

2 Berenguer M, Wright TL. Hepatitis C and liver transplantation. Gut 1999;45:159-63.

Cattral MS, Krajden M, Wanless IR, Cameron R, Greig PD, Chung SW, et al. A pilot study of ribavirin therapy for recurrent hepatitis $\mathrm{C}$ virus infection after liver transplantarecurrent hepatitis C virus infection afe

-

Wane LJ, Lo SK, Riordan SM, Lau JY, Naoumov NV, Williams R. A randomised study comparing ribavirin an then alfa after liver transplantation. Hepatology 1998;27:1403-7.

5 Bizollon T, Palazzo U, Ducerf C, Chevallier M, Elliott M, Baulieux J, et al. Pilot study of the combination of interferon alfa and ribavirin as therapy of recurrent hepatitis C after liver transplantation. Hepatology 1997;26:500-4

\section{Eradication of Helicobacter pylori in functional dyspepsia}

\section{Study had several weaknesses}

EDITOR-Several weaknesses in Talley et al's study may explain its failure to detect symptomatic benefit from eradicating infection with Helicobacter pylori in functional dyspepsia. ${ }^{1}$ The first is inadequate follow up. Of the three quarters of patients said to have completed the study, some did not reach their one year assessment. The outcome measurement even in those reaching the one year end point seems to have been inadequate as symptom diary cards in which only three fifths were completed were considered acceptable. The proportion of randomised patients reaching the one year end point with complete outcome documentation needs to be reported.

In our study, funded by the Medical Research Council, 318 patients were randomised and $97 \%$ were fully reassessed one year after treatment. ${ }^{2}$ This reassessment showed a significant benefit of active compared with placebo treatment of $14 \%$ $(95 \%$ confidence interval $7 \%$ to $22 \%$; $\mathrm{P}<0.001)$. Even before the problems with follow up are taken into account, Talley et al's study only had the power to detect a benefit of $20 \%$, and its negative result in no way refutes the findings of our study.

Another problem in the authors' study is that, despite functional dyspepsia being common, half of the 40 centres recruited fewer than six patients. How representative were these patients of patients with the disorder? The symptom characteristics indicate that patients with the motility type of functional dyspepsia-the group least likely to benefit from eradication treatment-were overrepresented, making up most of those randomised. In our study every patient fulfilling the entry criteria was randomised apart from nine $(3 \%)$ who did not consent.

Despite the above shortcomings, there are several pointers in Talley et al's study towards symptomatic benefit from eradicating $H$ pylori. Resolution of symptoms was $8 \%$ greater in those who became negative for $H$ pylori than in those who remained positive for it, and the use of antacids was $18 \%$ less. Furthermore, symptoms resolved in $15 \%$ more of those with little or no persisting $H$ pylori gastritis, and this was highly significant $(\mathrm{P}=0.008)$ even on secondary analysis.

The magnitude of benefit of $14 \%$ over placebo treatment detected by our study, but missed by studies of inadequate power, is clinically important. The treatments currently used, such as anti-secretory agents and anti-nociceptive agents, produce a benefit of only $10 \%$ over placebo. ${ }^{3}$ Consequently, the benefit of treatment to eradicate $H$ pylori is at least as great as that of any other currently available treatment. Moreover, the benefit is achieved by a single week's course of treatment rather than by long term, expensive maintenance treatment.

Kenneth E L McColl professor of gastroenterology

K.E.L.McColl@clinmed.gla.ac.uk

Derek Gillen lecturer in gastroenterology

Anthea S Dickson clinical research supervisor

University Department of Medicine and

Therapeutics, Western Infirmary, Glasgow G11 6NT

Competing interests: Professor McColl has received lecture fees and funds for research and for a member of staff from several companies that produce proton pump inhibitors.

1 Talley N J, Janssens J, Lauritsen K, Racz I, Bollin Sternevald E. Eradication of Helicobacter pylori in (a) placebo conom

2 McColl KEL, Murray L, El-Omar E, Dickson A, El-Nujumi A, Wriz A, et al. Symptomatic benefit from eradicating Helicobacter pylori infection in patients with nonulcer dyspepsia. N Engl J Med 1998;339:1869-74.

3 Talley NJ, Meineche-Schmidt M, Pare P, Duckworth M, Raisanen P, Pap A, et al. Efficacy of omeprazole in functiona dyspepsia: double-blind, randomised, placebo-controlled trials (the Bond and Opera studies). Aliment Pharmacol Ther 1998;12:1055-65.

4 Read NW, Abitbol JL, Bardhan KD, Whorwell PJ, Fraitag B. Efficacy and safety of the peripheral kappa agonist fedotozine versus placebo in the treatment of functional dyspepsia. Gut 1997;41:664-8.

\section{Authors' reply}

EDitor-McColl et al have several misconceptions about our paper. Recently, three high quality randomised controlled trials have addressed the question of eradication of Helicobacter pylori in functional dyspepsia and relief of symptoms: ours (the ORCHID trial), ${ }^{1}$ the OCAY trial, ${ }^{2}$ and the Medical Research Council trial. ${ }^{3}$ Only the MRC trial reached significance despite a similar sample size in all three trials. The ORCHID trial was the only one to include a placebo arm (rather than omeprazole). As the ORCHID and OCAY trials were otherwise closely similar in design, reference to all three is relevant here.

Follow up was adequate in all the trials; $87 \%$ of patients who completed the ORCHID trial and $97 \%$ of those who completed the OCAY trial had valid diary data. The outcome in the ORCHID and OCAY trials was similar. When the results of these two trials are combined $(n=603)$ the therapeutic gain in terms of complete symptom relief over placebo was 5\%, which was not significant $(95 \%$ confidence interval $-2 \%$ to $11 \%$ ). The power of the ORCHID 
and OCAY trials combined to detect a true difference of $10 \%$ (assuming a $15 \%$ response to placebo and $25 \%$ for active treatment, with an $\alpha$ level of 0.05 ) was $84 \%$; for a difference of $15 \%$ the power was over $99 \%$. Therefore, the assertion that the negative trials were underpowered is rejected.

There were no important centre effects in the ORCHID trial. When the analysis was restricted to only centres that recruited more than six patients, symptom relief was $21 \%$ in both the active and placebo arms.

Was the MRC trial flawed? The issue of the low placebo response (7\%) merits special attention. In the MRC trial few patients had endoscopic follow up, although it was known that the region where patients were recruited has a high background prevalence of ulcer disease in people infected with $H$ pylori. ${ }^{4}$ Conceivably, therefore, after placebo treatment many unrecognised cases of ulcer relapsed over 12 months, resulting in an exceptionally low placebo response. Did the MRC trial therefore reach the wrong conclusion because of the patient population included?

When the results from the three trials are pooled the therapeutic gain over placebo was $8 \%$ ( $3 \%$ to $13 \%, \mathrm{P}=0.003$ ), but there was also significant inhomogeneity when the MRC trial was included $(\mathrm{P}=0.04$, Breslow Day test). The overall results support the view that the patient populations were different.

Our trial (the ORCHID trial) produced a robust result. Treatment to eradicate $H$ pylori in functional dyspepsia is disappointing compared with placebo in terms of symptom relief 12 months after treatment. The results do not preclude a symptom response to eradication treatment in some cases, but the number who will truly benefit must be small.

Nicholas J Talley professor

Department of Medicine, University of Sydney,

Nepean Hospital, Penrith, New South Wales 2751, Australia

talley@pnc.com.au

Karsten Lauritsen specialist

Department of Medical Gastroenterology, Odense University, Denmark 5000

Elisabeth Bolling-Sternevald scientis

Department of Biomedicine and Surgery,

University of Linkøping, Molndal, Sweden 58185

Competing interests: NJT has been a consultant for Astra Hässle (Sweden) and Abbott Laboratories (USA). EB-S is an employee of Astra Hässle (Molndal, Sweden).

1 Talley NJ, Janssens J, Lauritsen K, Racz I, BollingSternevald E. Eradication of Helicobacter pylori in funtional $\mathrm{E}$. Erat in functional dyspepsia: randomised double blind placebo 318:833-7. (27 March) months' follow up. BMJ 1999

Blum AL, Talley NJ, O'Morain C, van Zanten SV, Labenz J Stolte M, et al. Lack of effect of treating Helicobacter pylor infection in patients with nonulcer dyspepsia. Omeprazole plus Clarithromycin and Amoxicillin Effect On Year after Treatment (OCAY) Study Group. N Engl J Med 1998; 339:1875-81.

3 McColl K, Murray L, El-Omar E, Dickson A, El-Nujumi A, Wirz A, et al. Symptomatic benefit from eradicating Helicobacter pylori infection in patients with nonulcer dyspepsia. N Engl J Med 1998;339:1869-74.

4 McColl KE, El-Nujumi A, Murray L, El-Omar E, Gillen D, Dickson A, et al. The Helicobacter pylori breath test: a sourDickon A, et al. The Helicobac rogate marker for peptic ulcer disease in dyspeptic
patients. Gut 1997;40:302-6.

\section{UK trial of policy of neonatal ECMO provides most reliable information so far}

EDITOR-Shann suggests that striking advantages ascribed to extracorporeal membrane oxygenation in the United Kingdom trial of this treatment versus conventional ventilatory management may have been due to "better" care in the extracorporeal membrane oxygenation centres rather than to the treatment itself. ${ }^{2}$ As principal investigators for the trial, we disagree.

The trial was designed to be pragmatic in the sense that, as much as possible, it reflected the then-current clinical policies and practices; results were therefore likely to be applicable outside the trial. In keeping with this philosophy, only hospitals familiar with providing intensive care on a regular basis were permitted to randomise patients directly into the study. Eligible infants arising in other settings were accepted only if referral to a tertiary unit had already been organised; we made it clear that any conventional care after randomisation would be the responsibility of the tertiary unit. In addition, a preplanned subgroup analysis did not find differential benefit for extracorporea membrane oxygenation when the hospitals providing conventional ventilatory management were stratified in terms of whether or not they were teaching hospitals.

Babies transferred to an extracorporeal membrane oxygenation centre were not usually directly under the care of experienced neonatologists (although neonatology support was made available). In general these centres had strong experience in cardiothoracic intensive care and more equipment and staff specific to extracorporeal membrane oxygenation (especially perfusionists and surgeons), although only one of the five centres had substantial experience of extracorporeal membrane oxygenation before the trial started.

The reference to the comparison between paediatric intensive care in Trent with that in Victoria is unhelpful in this particular debate. ${ }^{3}$ In that study the only term infants from Trent included were those requiring cardiac care, a small number requiring some forms of specialist surgery, and babies receiving extracorporeal membrane oxygenation. All of these infants were cared for in high volume specialist centres.

In the United Kingdom transfer remains an integral part of the extracorporeal membrane oxygenation policy. Because of the tiered service structure a few infants need to be transferred in order to receive optimal conventional ventilatory management. Had the Australian neonatal community, with its highly centralised system, accepted the invitation to participate in the United Kingdom trial it would be in a better position today to address Shann's question as to whether extracorporeal membrane oxygenation (including transfer to a specialist centre) is more effective than conventional ventilatory management (including such transfer). The United Kingdom trial provides the most reliable and unbiased information about the role of a policy of neonatal extracorporeal membrane oxygenation.

Diana Elbourne senior lecturer

Medical Statistics Unit, London School of Hygiene and Tropical Medicine, London WC1E 7HT d.elbourne@1shtm.ac.uk

Adrian Grant director

Health Services Research Unit, University of Aberdeen, Aberdeen AB25 2ZD

David Field professor of neonatal medicine Department of Child Health, University of Leicester, Leicester LE1 5WW

Charles Skeoch consultant in medical paediatrics Department of Child Health, University of Glasgow, Glasgow G4 0NA

Ann Johnson developmental paediatrician National Perinatal Epidemiology Unit, University of Oxford, Oxford OX2 6HE

1 Shann F. UK trial of extracorporeal membrane oxygenation gave biased estimate of efficacy. BMJ 1999:318:738. tion gave bise

2 UK Collaborative ECMO Trial Group. UK collaborative randomised trial of neonatal extracorporeal membrane oxygenation. Lancet 1996;348:75-82

3 Pearson G, Shann F, Barry P, Vyas J, Thomas D, Powell C, et al. Should paediatric intensive care be centralised? Trent versus Victoria. Lancet 1997;249:1213-7.

\section{Managing atrial fibrillation in elderly people}

\section{What should target international normalised ratio be?}

EDITOR-Factual errors require correction in English and Channer's editorial on managing atrial fibrillation in elderly patients. ${ }^{1}$ The authors state that the Boston area anticoagulation trial for atrial fibrillation and the stroke prevention in atrial fibrillation III (SPAF III) trial showed that anticoagulation to an international normalised ratio of 1.5-3.0 is safe and effective, referencing a 1994 review article to support this statement. The SPAF III trial was not published until $1996,{ }^{2}$ so the reference is presumably to the SPAF II trial.

The target for anticoagulation in the Boston area anticoagulation trial for atrial fibrillation was a prothrombin time ratio of 1.2-1.5 (corresponding roughly to an international normalised ratio of 2.0-3.0), ${ }^{4}$ whereas in the SPAF II trial it was a prothrombin time ratio of 1.3-1.8 (roughly an international normalised ratio of 2.0-4.5). The SPAF III trial showed that in high risk patients fixed dose warfarin (initial international normalised ratio 1.2-1.5) plus aspirin was less effective than adjusted dose warfarin (international normalised ratio 2.03.0). A subsequent trial of fixed dose warfarin was stopped early in the light of the results of the SPAF III trial. At stopping, there was a trend favouring adjusted dose warfarin. ${ }^{5}$

In patients with atrial fibrillation treated with warfarin, current evidence suggests that the best ratio of benefit to risk is achieved when the target international normalised ratio is 2.0-3.0.

Tim Lancaster general practitioner Jericho Health Centre, Oxford tim.lancaster@dphpc.ox.ac.uk 
1 English KM, Channer KS. Managing atrial fibrillation in elderly people. BMJ 1999;318:1088-9. (24 April.)

2 Stroke Prevention in Atrial Fibrillation Investigators Adjusted-dose warfarin versus low-intensity, fixed-dose warfarin plus aspirin for high-risk patients with atria fibrillation. Lancet 1996;348:633-8

3 Stroke Prevention in Atrial Fibrillation Investigators. Warfarin versus aspirin for prevention of thromboembolism in atrial fibrillation. Lancet 1994;343:687-91.

4 Boston Area Anticoagulation Trial for Atrial Fibrillation Investigators. The effect of low-dose warfarin on the risk of trestigator. The eflect of low-dose war atin Engl J Med 1990;323:1505-11.

5 Gullov AL, Koefoed BG, Petersen P, Pedersen TS Gullov AL, Koefoed BG, Petersen P, Pedersen TS, Andersen ED, Godtredsen J, et al. Fixed minidose warfarin and aspirin alone and in combination v adjusted-dose warfarin for stroke prevention in atria fibrillation: Second Copenhagen atrial fibrillation, aspirin, and anticoagulation study. Arch Intern Med 1998;158:
1513-21.

\section{Patients presenting acutely should be} given anticoagulation with heparin

EDITOR-English and Channer perpetuate the myth that cardioversion of atrial fibrillation is safe without anticoagulation if the arrhythmia has been present for less than 48 hours. ${ }^{1}$ There is no evidence to substantiate this assumption, and the American College of Chest Physicians in fact makes no recommendations, merely observing that the usual practice is not to give anticoagulant treatment.

The past assumption that 48 hours is insufficient time for thrombus to form has been shown to be incorrect, thrombus occurring within a few hours of the development of atrial fibrillation in some patients and being present in 14\% of patients presenting acutely with the arrhythmia. ${ }^{3}$ Furthermore, recent studies using transoesophageal echocardiography have challenged the view that only preformed thrombus poses a risk after cardioversion. ${ }^{4}$

In up to $35 \%$ of patients spontaneous contrast in the atria either develops or worsens after cardioversion (such contrast in the atria is associated with the formation of atrial thrombi). In addition, atrial thrombus has been found after cardioversion when none was present before, indicating subsequent formation; left atrial appendage emptying velocities on average decrease despite the development of coordinated electrical activity after cardioversion, presumably due to "stunning" of mechanical function. This may produce an increased potential for thrombus to form in the left atrial appendage after cardioversion.

Further evidence for the predisposition of the atria after cardioversion to develop thrombus comes from studies that have used transoesophageal echocardiography to attempt to negate the need for anticoagulation, the premise being that if no thrombus was shown then no anticoagulation was required for cardioversion. However several thromboembolic complications have been reported from these studies. ${ }^{4}$ Although transoesophageal echocardiography is not perfect for excluding atrial thrombus, the number of embolic events exceeded those that would be expected if a small number of atrial thrombi were missed. This favours the assumption that thrombus develops in the atria after, and possibly as a consequence of, cardioversion.
For patients presenting acutely with atrial fibrillation we suggest giving anticoagulation with heparin immediately on presentation and, for those who require cardioversion, using transoesophageal echocardiography to exclude atrial thrombi before the procedure. We suggest that ora anticoagulation is continued for at least four weeks after the procedure. If transoesophageal echocardiography is not readily available an alternative strategy would be to give anticoagulants for three weeks and thereafter readmit the patient for elective cardioversion, continuing the anticoagulants for a further four weeks after the procedure.

Jamil Mayet senior registrar

j.mayet@ic.ac.uk

Balvinder Wasan specialist registrar

Prapa Kanagaratnam research fellow

Department of Cardiology, St Mary's Hospital,

National Heart and Lung Institute, Imperial

College, London W2 1NY

1 English KM, Channer KS. Managing atrial fibrillation in elderly people. BMJ 1999;318:1088-9.(24 April.)

2 Laupacis A, Albers G, Dalen J, Dunn M, Feinberg W, Jacob-

Laupacis A, Albers G, Dalen J, Dunn M, Feinberg W, Jacob-
sen A. Antithrombotic therapy in atrial fibrillation. 4th ACCP consensus conference on antithrombotic therapy. ACCP consensus conf

3 Stoddard MF, Dawkins PR, Prince CR, Ammash NM. Left atrial appendage thrombus is not uncommon in patient with acute atrial fibrillation and a recent embolic event: transesophageal echocardiographic study. $\mathrm{J} \mathrm{Am} \mathrm{Coll}$ Cardiol 1995;25:452-9.

4 Mayet J, More RS, Sutton GC. Anticoagulation for cardioversion of atrial arrhythmias. Eur Heart J 1998;19:548-52.

\section{Authors' reply}

EDITOR-Elderly patients with atrial fibrillation gain the most benefit from anticoagulation, but the international normalised ratio should be as low as is efficacious to minimise bleeding complications. We recognise that current guidelines suggest maintaining the ratio at 2.0-3.0, but we presented data from two trials suggesting that anticoagulation to a ratio of $>1.5$ may be effective

Lancaster mentions that the target prothrombin time ratio in the Boston area anticoagulation trial for atrial fibrillation was 1.2-1.5 and states that this corresponds roughly to an international normalised ratio of 2.0-3.0. Conversion of the prothrombin time ratio to the international normalised ratio depends on the thromboplastin used by each laboratory. In the Boston trial this prothrombin time ratio corresponded to an international normalised ratio of 1.5-2.7. Exposure analysis in the SPAF III trial showed a reduction in primary event rates to only $2 \%$ in those with an international normalised ratio of 1.5-1.9 (with additional treatment with aspirin), with an added reduction of only $0.5 \%$ with an international normalised ratio $\geqslant 2.5^{2}$ (figure).

Mayet et al voice concerns regarding cardioversion of atrial fibrillation of acute onset without prior anticoagulation. Data from randomised trials are limited, but there is evidence supporting its safety. Among 357 patients with successful cardioversion from atrial fibrillation of $<48$ hours, only three thromboembolic events occurred $(0.8 \%) .^{3}$ Although the study was underpowered, no significant benefit was seen in the $42 \%$ given anticoagulants.

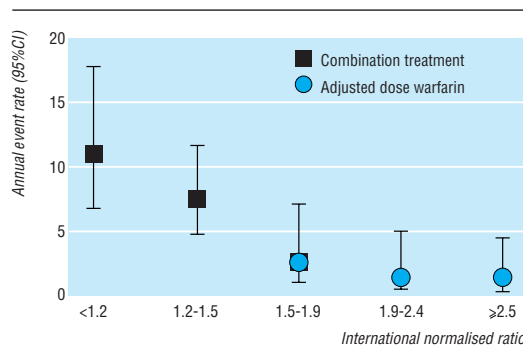

Event rates for ischaemic stroke or systemic emboli (primary events) as function of actual exposure to various intensities of anticoagulation at start of

follow up interval. International normalised ratio of 1.5-1.9 includes patients assigned to both treatment arms. Reproduced with permission from reference 2

Stoddard et al's study showing atrial thrombus on transoesophageal echocardiography in $14 \%$ of patients with atrial fibrillation lasting $<72$ hours has intrinsic selection bias, and its result should be viewed with caution. ${ }^{4}$ The American College of Chest Physicians' conclusion is that "antithrombotic therapy is not recommended for cardioversion of supraventricular tachycardia or AF [atrial fibrillation] of less than 2 days' duration."

The role of transoesophageal echocardiography in acute and chronic atrial fibrillation remains controversial, and trial data are scarce. Mayet et al state correctly that exclusion of atrial thrombus by transoesophageal echocardiography does not preclude embolism during or after cardioversion, theorising that atrial thrombus forms afterwards. Equally, the source of emboli may be the aorta or carotid vessels, not the atria at all, or the sensitivity of transoesophageal echocardiography may be less than previously assumed.

Although unsupported by controlled trial data, the suggestion of four weeks' anticoagulation after cardioversion from acute atrial fibrillation may be of value in preventing formation of thrombus after cardioversion. However, their suggestion of immediate heparinisation is not therapeutic, and pre-procedure transoesophageal echocardiography does not exclude thromboembolic complications. Moreover, the suggestion of three weeks' anticoagulation before cardioversion if transoesophageal echocardiography is unavailable is unnecessary and disadvantageous to the patient

K M English research registrar Kate.english@csuh.trent.nhs.uk

K S Channer consultant cardiologist

Department of Cardiology, Royal Hallamshire Hospital, Sheffield S10 2JF

\footnotetext{
1 Boston Area Anticoagulation Trial for Atrial Fibrillation Investigators. The effect of low dose warfarin on the risk of stroke in patients with nonrheumatic atrial fibrillation. $N$ Engl J Med 1990;323:1505-11

2 Stroke Prevention in Atrial Fibrillation Investigators. Adjusted dose warfarin versus low intensity, fixed dose warfarin plus aspirin for high risk patients with atrial fibrillation: Stroke prevention in atrial fibrillation III randomised controlled trial. Lancet 1996;348:633-8.

3 Weigner MJ, Caulfield TA, Danias PG, Silverman DI, Manning WJ Risk for clinical thromboembolism associated with conversion to sinus rhythm in patients with atrial fibrillation lasting less than 48 hours Ann Intern Med
} 
4 Stoddard MF, Dawkins PR, Prince CR, Ammash PR. Left atrial appendage thrombus is not uncommon in patients with acute atrial fibrillation and a recent embolic event: a transesophageal echocardiographic study. J Am Coll Cardiol 1995;25:452-9.

5 Laupacis A, Albers G, Dalen J, Dunn M, Feinberg W, Jacobsen A. Antithrombotic therapy in atrial fibrillation. Fourth ACCP consensus conference on antithrombotic therapy. Chest 1995;108:352-9S.

\section{Non-specific abdominal pain during school term may be due to viral infections then}

EDITOR-Williams et al conclude that psychological and behavioural factors may explain why children were more likely to have abdominal pain during the school term than the holidays. ${ }^{1}$ As non-specific abdominal pain commonly accompanies viral upper respiratory tract infections and mesenteric adenitis ${ }^{2}$ the rise in admission rates during term time may also reflect an increase in the transmission of viral infections among children then.

Raman Malhotra specialist registrar

Department of Ophthalmology, Royal Berkshire Hospital, Reading RG1 5AN

raman.kavita@virgin.net

1 Williams N, Jackson D, Lambert PC, Johnstone JM. Incidence of non-specific abdominal pain in children during school term: population survey based on discharge diagnoses. BMJ 1999;318:1455. (29 May.)

2 Hull D, Johnstone DI. Essential paediatrics. 2nd ed. London Churchill Livingstone, 1987:148-9.

\section{Tackling health inequalities in primary care}

Exploring possible solutions to a problem is more important than describing the problem

EDITOR-Smeeth and Heath discuss how health inequalities might be tackled in primary care. ${ }^{1}$ We endorse their views on the importance of accurate measurement of social position and their reminder that it is people who are most at risk of serious disease who have most to gain from effective medical interventions. ${ }^{2}$

The authors emphasise the assessment of socioeconomic factors in individual consultations. Although this may sometimes be important, in general it is not the main issue, and their suggestion of yet another task to be completed in an already crowded agenda may put some people off. The recording of accurate, useful data on social position need not involve general practitioners directly at all and can be recorded at registration.

Occupational class and place of residence are not fixed, and some social mobility is now a feature of society in the United Kingdom. ${ }^{3}$ It should be sufficient, however, simply to ask patients to inform the practice of changes in their address or employment-as most general practices do now. The main use of such information is not to guide the treatment of individuals but to allow rational resource allocation at practice or primary care group level. Poorer people experience more serious disease in their shorter lives than their more affluent counterparts, which has implications for doctors who work with them. These issues have been considered in detail in relation to child health

Imprecision in the measurement of the material circumstances that a person experiences has probably led to dilution of estimates of the health consequences of these circumstances. In other words, we could improve our descriptions of health inequalities and when we do they will probably be even more striking than they are at present. Description of a problem is important but so is exploration of a solution. We hope that the bigger role for primary care lies in exploring a solutionthrough advocacy, rational and equitable delivery of effective interventions, and political lobbying.

John Macleod clinical research fellow

Rhian Loudon Clinical research fellow

Health Inequalities Research Group, Department of General Practice, University of Birmingham,

Birmingham B15 2TT

j.a.macleod@bham.ac.uk

1 Smeeth L, Heath I. Tackling health inequalities in primary care. BMJ 1999;318:1020-1. (17 April.)

2 Davey Smith G, Egger M. Who benefits from medica interventions? BMJ 1994;308:72-4

3 Bartley M, Plewis I. Does health-selective mobility account for socioeconomic differences in health? Evidence from England and Wales, 1971-1991. I Health Soc Beha 1997;38:376-86

4 Hall DMB, ed. Health for all children. Report of the third joint working party on child health surveillance. 3rd ed. Oxford: Oxford University Press, 1996:1-40.

Doctors in less affluent areas don't have the time to collect more data

EDITOR-The identification of adverse socioeconomic factors can be instrumental in targeting resources to patients both at an individual level by general practitioners and more widely at a practice or primary care group level. The formal collection of such data by general practices, as advocated by Smeeth and Heath, ${ }^{1}$ is difficult.

I suspect that for most general practitioners the "largely opportunistic and possibly rather haphazard" appraisal of socioeconomic factors is part of their routine assessment at an individual level. It probably does not need to be put on a more formal footing. Socioeconomic data recorded by the practice could be used to allocate extra resources. For a practice to gain an extra slice of an already limited and apportioned cake, the data need to show higher need in one area than another Obtaining such relative data requires the cooperation of practices in more affluent areas in collecting data that will lead to a diminution in their own resources.

In less affluent areas with more socioeconomic problems general practitioners may find that surviving the workload limits the time available for recording data. In my practice of 7500 patients we found that to collect such data for the fourth national morbidity study we had to employ two full time workers. Simply asking patients to fill in questionnaires leads to piles of blank answer sheets from those unable to read and write or just too overwhelmed by social stresses to be bothered with another load of questions -just the people who most need help.

Perhaps time and resources could be better directed at improving the targeting of census and other nationally collected data to more local levels. Persuading general practitioners to take on recording this information on top of the myriad other demands on their time is going to be difficult.

Dougal Darvill general practitioner Hartcliffe Health Centre, Bristol BS13 0JP dougal.darvill@cyberphile.co.uk

1 Smeeth L, Heath I. Tackling health inequalities in primary care. BMJ 1999;318:1020-1. (17 April.)

\section{Authors' reply}

EDITOR-The assessment of socioeconomic factors in individual consultations is just one aspect of tackling social inequalities in health. Macleod and Loudon suggest that we think it is the main issue, or that simply describing social inequalities is sufficient. We do not think this. The main issue is that health inequalities occur because of the way society is organised, in particular because of inequalities in incomes. Tackling the underlying determinants of health inequalities requires the redistribution of money from rich people to poor people, ${ }^{12}$ but health workers have an important role. ${ }^{3}$ General practice cannot solve the problems of poverty and ill health, but surely we must have some contribution to make to the processes of mitigation. Are those at higher risk simply to be assigned to "usual care"? How can this possibly be justified?

Darvill argues that an assessment of socioeconomic factors is already part of routine practice. The evidence suggests otherwise. Our experiences suggest that for social determinants of health we know what we know; we are in blissful ignorance of the rest. For example, do we have complete knowledge of which parents of young children are unsupported, socially isolated, or living in poverty? Yet intensive health visiting for such families can help reduce the effects of disadvantage.

We propose a few simple questions at most, not the battery of information required for the national morbidity study. Research into the types of questions that could be used to measure socioeconomic health risk and to elicit opportunities for interventions to reduce inequalities is urgently needed. Such questions would not need to generate a massive additional workload. Possible examples include asking older patients whether they can afford to heat their homes in winter (as a measure of poverty) and whether they have regular contact with people they like (as a measure of social isolation). Targeting interventions and a more equitable allocation of resources require data at all levels, from individual patients to primary care groups and at regional, national, and international levels.

As Darvill argues, practices in affluent areas may well refuse to cooperate in the collection of data that would aid the process of redistribution to poorer areas, both within 
and between primary care groups. If primary care groups are to tackle inequalities effectively this is an issue that the government will have to address.

Liam Smeeth clinical lecturer

Department of Primary Care and Population

Sciences, Royal Free and University College

London Medical School, London N19 5NF

1.smeeth@ucl.ac.uk

Iona Heath chair

Health Inequalities Task Group, Royal College of General Practitioners, London SW7 1PU

1 Davey Smith G, Morris JN, Shaw M. The independent inquiry into inequalities and health. $B M J$ 1998;317:1465-6.

2 Davey Smith G, Dorling D, Gordon D, Shaw M. The widening health gap-what are the solutions? Bristol: Townsend Centre for International Poverty Research, 1998.

3 McCally M, Haines A, Fein O, Addington W, Lawrence RS, Cassell CK. Poverty and ill health: physicians can RS Cassell CK. Poverty and ill health: physicians can, and should,

4 Gulbrandsen P, Fugelli P, Hjortdahl P. General practitioners' knowledge of their patients' psychosocial problems: ers' knowledge of their patients' psychosocial problems: multipractice questionnaire survey. BMJ 1997;314:1014-8. 5 Olds DL, Eckenrode J, Henderson CR Jr, Kitzman H, Powers J, Cole R, et al. Long-term effects of home visitation on maternal life course and child abuse and neglect. Fifteen-year follow-up of a randomized trial. JAMA 1997; 278:637-48.

\section{Patients with tuberculosis can be managed effectively in the community}

EDITOR-Coker observes that the urgency of the response to tuberculosis reflects how society views those on its margins. ${ }^{1}$ In contrast, a recent report from New York stated that, despite a reluctance to impose restrictive measures of mandatory directly observed treatment, over $3 \%$ of patients with tuberculosis (over 200 patients) between 1993 and 1995 did receive regulatory orders. $^{2}$ These are two diametrically opposed positions to the public health response to the same disease.

In New South Wales, Australia, public health orders can be imposed under the Public Health Act 1991. Yet in over eight years, not a single order has led to a patient with tuberculosis being imprisoned. Notifications of over 500 cases of tuberculosis per year mean that over 4000 cases have been effectively managed in the community. Community based services have been able to manage every case of tuberculosis, using clinic based nurses with minimal involvement of medical staff; standardised treatment according to health department protocols; and directly observed treatment, which has been practised for over 30 years. Thus costs have been contained and levels of drug resistance have remained low.

Rather than investing in a good public health system and well resourced community based services, the United States seems to be using "deprivation of liberty" to solve not only its social problems ${ }^{4}$ but also its tuberculosis epidemic. This is an abuse of

Rapid responses
$\begin{aligned} & \text { Correspondence submitted electronically } \\ & \text { is available on our website www.bmj.com }\end{aligned}$

human rights and makes no sense in terms of public health.

Introducing cases of active tuberculosis into the closed environment of a prison is inherently dangerous. High levels of mobility within prisons, and between prisons and the community, facilitate transmission of tuberculosis between the community and prisons (in both directions) and create the situation in which epidemics in prisons occur. $^{5}$

London ought to be looking to effective programmes rather than copying yet another American mistake.

Michael H Levy director

Population Health, Corrections Health Service, PO Box 150 Matraville, NSW 2036, Australia

Garth Alperstein area community paediatrician Central Sydney Community Health Services, Camperdown, NSW 2050 Australia alpersteing@phu.rpa.cs.nsw.gov.au

\section{Coker R. Public health, civil liberties, and tuberculosis. $B M$ 1999:318:1434-5. (24 April) \\ 2 Gasner RM, Maw KL, Feldman GE, Fujiwara PI, Frieden TR. The use of legal action in New York City to ensure treatment of tuberculosis. N Engl J Med 1999;340:359-66. \\ 3 Dawson D. Tuberculosis in Australia: bacteriologically con- firmed cases and drug resistance, 1996. Report of the Aus- tralian Mycobacterium Reference Laboratory Network. Commun Dis Intell 1998;22:183-8 \\ 4 Stern V. A sin against the future: imprisonment in the world. London: Penguin, 1998. \\ 5 Coninx R, Eshaya-Chauvin B, Reyes H. Tuberculosis in prisons. Lancet 1995;346:1238-9.}

\section{Neuropsychiatric condition must be thoroughly assessed before treatment of hepatic encephalopathy}

EdiTOR-Soulsby and Morgan report current practice in the treatment of hepatic encephalopathy by dietary protein restriction. ${ }^{1}$ Both they and the authors of the accompanying editorial ${ }^{2}$ make much of the use of protein restriction in patients who are "neuropsychiatrically unimpaired." I would be interested to know how these patients were assessed.

In a study in 1996 Krieger et al showed, using detailed neuropsychological testing, that significant abnormalities could be detected in patients who were thought by their clinicians not to have encephalopathy at the time of testing. ${ }^{3}$ The authors of the editorial suggest further studies aimed at answering the questions related to dietary protein restriction in hepatic encephalopathy; these studies will have to take Krieger et al's findings into account.

M B Lewis specialist registrar in neurology St James's University Hospital, Leeds LS9 7TF m-k-lewis@email.msn.com

Competing interests: None declared.

1 Soulsby CT, Morgan MY. Dietary management of hepatic encephalopathy in cirrhotic patients: survey of current practice in United Kingdom. BMJ 1999;318:1391. (22 Mav.)

2 Seymour CA, Whelan K. Dietary management of hepatic encephalopathy: too many myths persist. BMJ 1999:318: 1364-5. (22 Mav)

Krieger S, Jau BM, Jansen O, Theilmann L, Geibler M, Krieger D Neuropsychiatric profile and hyperintense Globus pallidus on T1-weighted magnetic resonance image in liver cirrhosis. Gastroenterology 1996;111:147-55.

\section{Effects of Soho bomb were little compared with Omagh bomb}

EdiToR-Dornan does herself an injustice by stating that "my entire career had been trained for this moment" [at the scene of the Soho bomb]. ${ }^{1}$ Her training would not have covered the immediate care of severely injured people in a street setting while off duty.

Similar statements were common from distressed medical and nursing staff after the Omagh bombing of August 1998 and were often linked with feelings of self doubt and guilt about "not doing more" for the injured. Dealing with the dead and injured, coupled with negative self perceptions about personal responses and capabilities, to some extent explains the greatly increased incidence of clinical depression among staff, and probably all cases of post-trauma mental health syndromes. ${ }^{2}$ I wish that the editor had chosen to highlight Dornan's last sentence-"My family, friends, and boyfriend have let me talk or not, as I wish"-rather than the one used.

Although counsellors are available after such events, for staff as well as the public, Dornan intuitively recognises that empathy and understanding from family, friends, and work colleagues provide more powerful support than empathy from people we don't know, however expertly trained and well meaning they are. Perhaps it would be churlish to accuse the $B M J$ (a London based journal) of being parochial by devoting a page to the Soho bomb; I recall seeing nothing about Oklahoma, Nairobi, or Omagh, although of course maybe local medical practitioners did not submit items for inclusion.

The psychological damage to the members of the medical and nursing professions in Northern Ireland over the past 30 years is undeniably large, as they have cared for many of the 3500 people killed and 40400 injured there. ${ }^{3}$ This legacy is generally unrecognised by health service planners and remains unmeasured. Pro rata by population, civil unrest on a similar scale would have led to 130000 deaths in the United Kingdom from the "troubles" as a whole. ${ }^{4}$ Similarly, the equivalent of the Omagh bomb occurring in London would have led to 5000 dead, 65000 seriously injured, and a further 350000 requiring medical attention. ${ }^{5}$

Clive R Burges consultant occupational health physician

Tyrone and Fermanagh Hospital, Omagh, Co Tyrone, BT79 0NS sandra@killynure.in2home.co.uk

1 Dornan RIP. The Soho bomb. BMJ 1999;318:1429. (22 May.)

2 Absence and occupational health service statistics. Sperrin Lakeland Health and Social Services Trust 1998-9.

3 Northern Ireland Social Services Inspectorate, Northern Ireland Department of Health and Social Services. Living with the trauma of the "troubles." Belfast: Stationery Office of Northern Ireland, 1998:4.

4 Bloomfield K. We will remember them: report of the Northorn Ireland Victims Commissioner. Belfast: Stationery Office of Northern Ireland, April 1998:12.

5 Omagh renewal and beyond. A local consensus document. 1998 